\title{
Applying Salutogenesis in Higher Education
}

\author{
Mark Dooris, Sharon Doherty, and Judy Orme
}

\section{Introduction}

Universities are important organisations for health promotion - not only as contexts and vehicles for enhancing wellbeing, but also as partners in multisectoral health improvement and as contributors to citizenship development and societal change (Dooris et al., 2012). In the UK alone, there are 168 higher education providers with almost 2.4 million students and 440,000 staff (Higher Education Statistics Agency, 2020a, 2020b), whilst worldwide, it is estimated that by 2040 , there will be 594 million university students, an increase of nearly 500 million since the turn of the millennium (ICEF Monitor, 2018). This points to the substantial global potential offered by universities as settings in which and through which to promote public health.

Over centuries, there have been contrasting accounts regarding the general role of higher education in societies, which can be summarised as follows (Epigeum Ltd., 2012):

1. Universities as communities of learning and personal development (the 'liberal' theory)

2. Universities as sources of expertise and vocational identity (the 'professional formation' theory)

This chapter is a revision and update of work published in Mittelmark, M.B., Sagy, S., Eriksson, M., Bauer, G., Pelikan, J.M., Lindström, B., \& Espnes, G.A. (eds). (2017). The Handbook of Salutogenesis. Springer, Cham. DOI: https://doi.org/10.1007/978-3-319-04600-6

M. Dooris $(\bowtie)$

Healthy \& Sustainable Settings Unit, School of Community Health \& Midwifery, Faculty of Health \& Care, University of Central

Lancashire, Preston, UK

e-mail: mtdooris@uclan.ac.uk

S. Doherty

Preston, UK

J. Orme

Department of Health and Social Sciences, University of the West of England, Bristol, UK
3. Universities as creators of and test-beds for the evaluation and application of new knowledge (the 'research engine' theory, linked to the 'business and industry services' theory)

4. Universities as important contributors to society and societal change (the 'civic and community engagement' theory)

Reflecting on these divergent understandings, it can be argued that most universities now function in ways that seek a balance between these strands of thinking - even whilst there is arguably a worrying trend towards a more instrumental and utilitarian perspective, with their core purpose being viewed in terms of contribution to economic growth and 'production' of graduates able to 'get a good job' (McGowan, 2015).

Whilst universities have historically been viewed as elitist organisations, there has been an increased concern over recent years to widen access and strengthen diversity, alongside the opening up of an increasingly competitive higher education 'marketplace'. For example, the UK's focus on 'widening participation' has resulted in the profile of students becoming increasingly diverse - with more mature students, part-time students and students from a wider range of socioeconomic backgrounds, many of whom are the first in their family to attend a university (House of Commons, 2018).

The role of higher education as an instrument of societal change has long been acknowledged, and Brennan et al. (2004) suggest that universities achieve this not only through producing highly skilled graduates and economically motivated research outputs but also through helping to build new institutions of civil society and encouraging new cultural values. In the context of the 'widening participation' agenda, it has been argued that: 'by encouraging students from all backgrounds to come to university, universities can do more than almost any other institution to improve social mobility and justice' (Schwartz, 2003), whilst the broader impact on local and regional communities is widely recognised in terms 
of employment, knowledge exchange, the built environment and social/community development (Centre for Urban and Regional Development Studies, 1994). More widely, the growing movement for 'civic universities' recognises that higher education institutions are key 'anchor institutions' and 'hugely important to the economic, social, cultural and environmental wellbeing of the places in which they are located' (UPP Foundation, 2019, p.4) and calls for strengthened and connections between universities and their localities.

\section{Promoting Health and Well-Being in the University Setting: An Overview}

For many years, universities have provided a key setting for the implementation of interventions on various health issues, leading to student-focused guidance on drugs, alcohol, mental health and other key themes (e.g. Crouch et al., 2006; Grant et al., 2002; Polymerou, 2007; Universities UK, 2000). Until relatively recently, these themes have tended to be constructed as 'problems' relating to risk-taking behaviour and ill-health, a focus mirrored by the traditional focus on reducing staff illness and sick leave caused by stress and other issues.

Aligned to Antonovsky's focus on health maintenance processes, there have, however, been encouraging signs of the higher education sector shifting away from a reductionist illness-oriented approach: This has been signalled, firstly, by increased use of the language of well-being and resilience (Marshall \& Morris, 2011; Shutler-Jones, 2011; Steuer \& Marcs, 2008) and, secondly, by a growing interest in moving beyond single topics and population subgroups to embrace a more strategic and comprehensive 'whole university' approach that embraces students, employees and the wider community (Dooris \& Doherty, 2009; Orme \& Dooris, 2010).

This 'Health Promoting University' approach endorses the Ottawa Charter (WHO, 1986) in its assertion that 'Health is created and lived by people within the settings of their everyday life; where they learn, work, play and love'. It is located within the field of settings-based health promotion, which Kickbusch (1996) has argued is salutogenic in orientation - 'shifting the focus from the deficit model of disease to the health potentials inherent in the social and institutional settings of everyday life'.

Importantly, the Health Promoting Universities approach is customised to the higher education context in recognition that universities have their own distinctive ethos and culture. Echoing the earlier discussion concerning the purpose of higher education, Dooris et al. (2012) have proposed that this whole system perspective needs to consider the multiple roles of universities - as centres of learning and development; as foci for creativity and innovation; as places where students undergo life transition and where citizenship is developed via future shaping of students and staff; as workplaces and businesses; and as resources for and influential partners within local, regional, national and global communities.

The vision and aspirations for this whole system approach are encapsulated in the influential Okanagan Charter (2015: 2 ), the culmination and collective outcome of the 2015 International Conference held in Canada:

'Health Promoting Universities and Colleges transform the health and sustainability of our current and future societies, strengthen communities and contribute to the wellbeing of people, places and the planet. Health-promoting universities and colleges infuse health into everyday operations, business practices and academic mandates. By doing so, health-promoting universities and colleges enhance the success of our institutions; create campus cultures of compassion, wellbeing, equity and social justice; improve the health of the people who live, learn, work, play and love on our campuses; and strengthen the ecological, social and economic sustainability of our communities and wider society'.

Reflecting its whole system focus, the Charter goes on to issue two calls to action - to embed health into all aspects of a university's culture, across its administration, operations and academic mandates; and to lead health promotion action and collaboration locally and globally. The first involves weaving health into the institution's various policies so that they support the flourishing of people, campuses, communities and the planet; creating environments that support health, well-being, sustainability and resilience; fostering thriving, empowered, connected and resilient campus communities; supporting personal development to enable students and staff to thrive and achieve their full potential; and creating or reorienting services to enhance health and well-being, optimise human and ecosystem potential and promote a supportive organisational culture. The second focuses on enhancing research for health promotion; positioning the university as a leader and advocate for local and global action; and integrating health, well-being and sustainability in and across multiple disciplines, so that students gain a critical understanding and become fired up as change agents and global citizens in families, communities, workplaces and society as a whole.

The approach focuses not only on tackling the very real health problems experienced by students and staff but also on enabling university communities to thrive. Whilst not explicit in its use of salutogenic terminology, this can be readily understood to address the question, 'how can movement towards the health pole of the health-ease/dis-ease continuum be facilitated?' The application of the Okanagan Charter to health promotion practice in higher education within Aotearoa New Zealand has been discussed by Waterworth and Thorpe (2017). In doing so, they highlight 
the importance of a salutogenic orientation, noting how this can be supported by focusing on assets and strengths, incorporating multiple stakeholder voices and prioritising indigenous knowledge and perspectives.

A focus on human flourishing in the university context inevitably highlights those factors that enable people to make sense of their lives and is concerned with people experiencing a strong 'sense of coherence', which Antonovsky (1987) suggested predicted positive health outcomes. A 'sense of coherence' is a global orientation that expresses the extent to which one has a pervasive, enduring feeling of confidence that the stimuli deriving from one's internal and external environments in the course of living are structured, predictable and explicable (comprehensibility), that the resources are available to one to meet the demands posed by these stimuli (manageability), and that these demands are challenges worthy of investment and engagement (meaningfulness). The relationship between sense of coherence and health is understood to be mediated by what Antonovsky calls 'resistance resources', which can be both generalised and specific.

Interpreted in this way, by encouraging and enabling higher education institutions to adopt a whole system approach to creating environments and cultures that actively support health, well-being and community connectedness, the Health Promoting Universities approach plays a central role in making generalised and specific resistance resources available to students, staff and other stakeholders, thereby enabling a strengthened sense of coherence. An example of the former might be an explicit commitment to health-promoting campus design whilst an example of the latter might be the provision of targeted student and staff counselling services.

\section{Conceptualising Health Promoting Universities: A Salutogenic Whole System Approach}

In 1995, the Faculty of Public Health Medicine (1995) published a special issue of its newsletter, which argued that 'initiatives in universities have emerged more or less in parallel with projects on the health-promoting workplace, school and hospital, but - without the benefit of any national or international infrastructure - they are only just beginning to generate a momentum of research and development' (Beattie, 1995, p. 2). Around the same time, two English universities Lancaster and Central Lancashire - established Health Promoting University programmes and collaborated with WHO Europe in writing the first guidance publication on Health Promoting Universities (Tsouros et al., 1998). In parallel, a German Working Group was established in 1995, evolving into the German Network of Health Promoting Universities (Stock et al., 2010).
Over the past two decades, there has been a growing body of conceptual research on the healthy settings approach and its application to the higher education sector. Dooris (1998, 1999, 2001) draws on the early experience of developing and implementing the University of Central Lancashire's Health Promoting University initiative to describe and discuss the framing of a whole system approach and the successes and challenges. The work explicitly seeks to apply a settings approach, which is clearly rooted in salutogenic theory (Kickbusch, 1996). His 'social ecosystem' model (Dooris, 2001) identified inputs, processes and outputs and illustrated how the concept and approach of Health Promoting Universities offers a means of investing in the health and well-being of students and staff. It is argued that this can be done by balancing a traditional pathogenic focus on addressing health needs and problems with a salutogenic focus on harnessing a university's strengths, assets and potentials in order to support the well-being and flourishing of students, staff and the wider community.

More recently, this systems-based approach has been explored further (Dooris, 2006). It highlights opportunities for universities to increase understanding of health, wellbeing and sustainability and of their underpinning social, political, economic, cultural and environmental determinants. Furthermore, it illustrates how universities play a key role in shaping the development of knowledge, values and priorities amongst students and staff and how they have the power to shape their current and future influence within, outside and beyond the university.

Antonovsky (1996) asked what a community can do to strengthen its 'sense of coherence' - its comprehensibility, manageability and meaningfulness? The UK Healthy Universities Network has subsequently agreed on a model to elucidate its vision which aligns with Antonovsky's idea of a sense of coherence (see Fig. 30.1), that is a way of making sense of the world and a major factor in determining how well a person manages stress and stays healthy. Dealing particularly with the concept of meaningfulness, which Antonovsky believes to be the most important, Fig. 30.1, can help to generate a sense of meaning around a healthy university for staff, students and wider communities which helps to explain the important components in predicting positive health outcomes.

The model is underpinned by health promotion principles such as equity, partnership, participation, empowerment and holism (Rootman et al., 2001), and concerned with the achievement of deliverables and impacts. Whilst there are no universally agreed indicators of impact, frameworks developed to facilitate self-review and implementation (Asean University Network-Health Promotion Network, 2017; UK Healthy Universities Network, undated; Dooris, Farrier, et al., 2018) anticipate changes across a range of organisational functions. Potential examples are higher quality health 
Fig. 30.1 Healthy

Universities - A model for conceptualising and applying the healthy settings approach to higher education. (Source: Dooris et al. (2010))

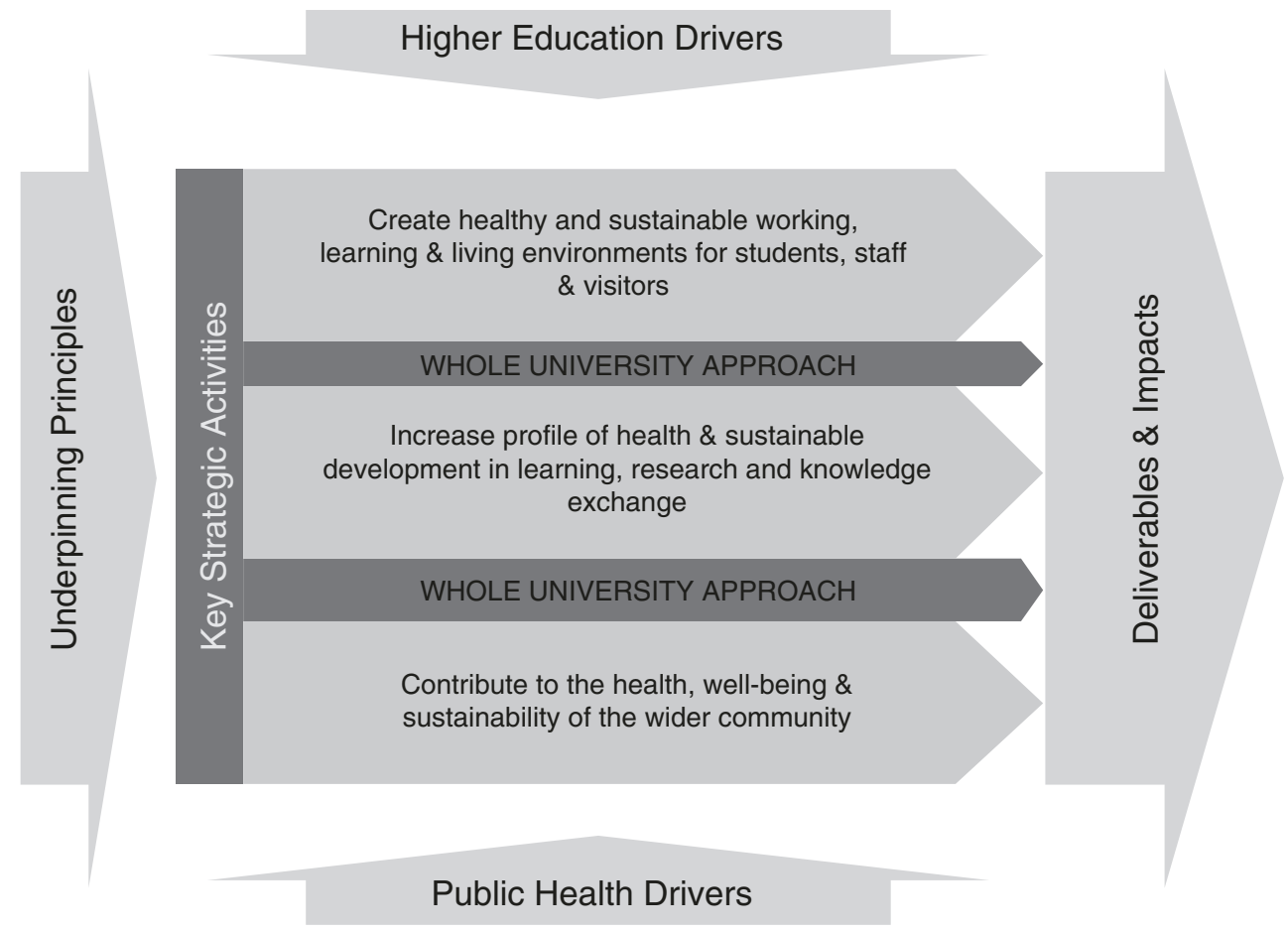

and welfare services; healthy and sustainable food procurement processes and catering services; increased personal responsibility for health among students and staff; and strengthened institution-level commitment to practise corporate social and environmental responsibility.

Central to it is a whole university approach, which involves working within and across three key strategic areas of activity - with the following aims:

- Creating healthy and sustainable learning, working and living environments (e.g. campus and building design, work-life balance policy and supportive management culture)

- Integrating health and sustainability within the mainstream activities of the university (e.g. health as multidisciplinary cross-cutting themes in curricula, research and knowledge exchange)

- Contributing to the health, well-being and sustainability of local, regional, national and global communities (e.g. health and sustainability impact assessment, locally embedded research, volunteering and outreach)

A whole university approach is also understood to be underpinned by health promotion values and to involve the following complementary strategies (Dooris, 2004, 2009):

- Anticipating and responding to higher education and public health drivers

- Securing 'top-down' leadership whilst also engaging 'bottom-up' stakeholder engagement and participation
- Combining long-term organisation development and change with high-visibility project work

- Balancing a pathogenic focus on addressing needs and problems with a salutogenic focus on harnessing a university's strengths, assets and potentials in order to support the well-being and flourishing of students, staff and the wider community

Focusing on the conceptualisation of a whole university approach, Dooris et al. (2019) report on an international study that explored vice-chancellors' and network members' understanding of and commitment to Health Promoting Universities. Through thematic analysis, several key themes emerged regarding the whole university approach, illustrated in Fig. 30.2: building a broad understanding and framing of health; developing a supportive ethos and culture; embedding health into the university and joining up areas of work; focusing on the whole population; and facing challenges and seizing opportunities. A concern to enhance positive well-being and harness assets and capabilities was explicit within this emerging model.

If practised in this 'whole system' way, the Health Promoting Universities approach offers opportunities to deliver important contributions to health, well-being and overall business performance and productivity. Furthermore, Health Promoting Universities can make an important contribution to intersectoral health promotion through sensitising students (and staff) across multiple disciplines to a range of health issues and 'future shaping' them as they clarify values, grow intellectually and develop capabilities that can enhance current and future citizenship within families, com- 


\section{Broad Understanding and Framing of Health}
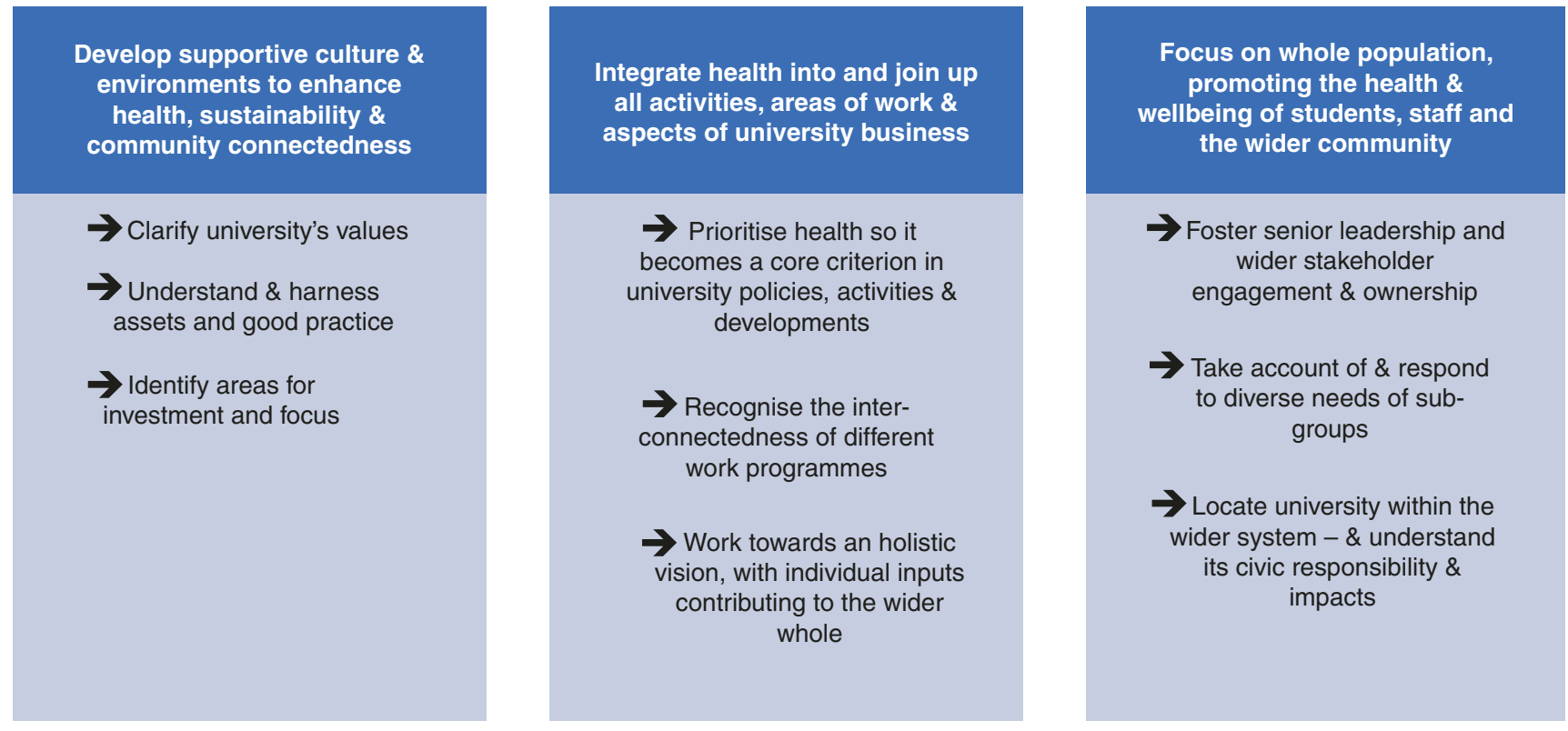

Opportunities

Challenges

Fig. 30.2 A whole university/whole system approach to health, wellbeing and sustainability (Adapted from Dooris, Powell, \& Farrier, 2018. This figure has been developed with use of the publication

munities, workplaces and society as a whole (Dooris et al., 2010; Dooris, Farrier, et al., 2018).

\section{Empirical Research on Health Promoting Universities}

Beyond the conceptual research detailed above, academic literature focused on Health Promoting Universities has largely described project delivery or reported on specific research studies relating to particular aspects of health promotion practice as summarised below. Whilst few publications report on research or programme implementation that has explicitly used salutogenesis or its component constructs as a framework, many have been framed within the broad theoretical contexts discussed above - emphasising how universities can provide supportive environments and resources; foster the development of personal strengths and empowerment; and encourage a focus on positive well-being.

Dooris $(1998,2001)$ reports on an evaluation of the first two years of the University of Central Lancashire's Healthy University initiative, concluding that there is value in locating health promotion interventions within a holistic framework which considers the university setting as an organisational whole and appreciates that it is influenced by broader contexts and determinants. This is echoed in a Royal
'Healthy Universities: Whole University Leadership for Health, Wellbeing and Sustainability' which is owned by Advance HE. (C) 2018 Advance HE. All rights reserved)

College of Psychiatrists (2011) report on the mental health of students, which states:

The 'Healthy Universities' initiative has adopted an ambitious rationale in relation to student health. The university or college is seen not only as a place of education but also as a resource for promoting health and well-being in students, staff and the wider community ... The 'Healthy Universities' systemic and holistic approach is commended and should be adopted as widely as possible.

Xiangyang et al. (2003) report on the development of health-promoting universities across Beijing, acknowledging the importance of a shift in focus from treating illness to prevention and health promotion, highlighting the centrality of creating health-supportive environments and concluding that the university community can benefit greatly from implementing health promotion campaigns based on the principles of the Ottawa Charter. Meier et al. (2006) discuss the contribution of health discussion groups to health promotion at the University of Bielefeld, concluding that they offer a valuable means of increasing students' participation and empowerment and of influencing strategic decisionmaking. An earlier study at the same university examined students' health-related behaviours (Stock et al., 2001) and, whilst framed in terms of 'health needs', highlighted the importance of also focusing on health potentials and personal resources. 
Coffey and Coufopoulos (2010) report on students undertaking a health needs assessment at Liverpool Hope University. Whilst the focus on needs would seem to locate the work outside of salutogenesis, the approach reflects a belief that a health promotion curriculum should itself enable people to increase control over and improve their health. Knight and La Placa (2013) report on a pilot Healthy University initiative at Greenwich University. Using a settings approach that sees the organisation as a key determinant of its members' health and well-being, this has prioritised the allocation of resources to activities that will create sustainable health-enhancing processes.

A number of relatively recent studies do articulate the centrality of the salutogenic perspective more explicitly. Reporting on a two-year feasibility project concerned with the establishment of University of Brighton as a Health Promoting University, Davies and Hall (2011) highlight the connections with core agendas such as recruitment, retention and productivity and suggest that the process can be a valuable mechanism for harnessing and adding value to existing good practice. Emphasising the importance of applying Ottawa Charter principles such as building healthy policy and creating supportive environments, the report explicitly references salutogenesis. Similarly, in exploring the application of a whole system approach to food within the university context, Doherty et al. (2011) locate their discussion within the Healthy Universities framework, which they argue has an explicitly salutogenic orientation.

One doctoral study examined two UK case studies, one 'exemplar' and one 'contrary', and found that the university adopting an explicit commitment to the Health Promoting Universities approach displayed features associated with a salutogenic organisation, with people feeling respected, supported and valued (Newton et al., 2016). Furthermore, these characteristics were viewed by senior leaders to be part of, rather than separate from, core business. The authors concluded that 'although it is not possible to evidence a causal relationship between the adoption of a healthy university approach and a salutogenic organisational culture, the contrasting case studies do suggest that such benefits may well be catalysed or reinforced by an intentional and explicit commitment to health and wellbeing' (p.63).

Innstrand and Christensen (2018) report on ARK, a holistic and systematic Norwegian health promotion intervention programme underpinned by the Health Promoting Universities settings approach and adapted for staff working in higher education. It concludes that the programme's key strengths derive in part from its salutogenic perspective focusing on strengthening positive health assets and potentials. Reporting on research examining the relationship between personal, university, home and community influences on the mental health status of Australia's university students, Usher (2019, p.149) concludes that: 'A dedicated and strategic commitment to embedding university policies aimed at heightening students' health and wellbeing sustainably...provides the perfect springboard for coordinated action to develop college campuses which can be considered health-promoting or salutogenic'.

\section{Research Relating to Salutogenesis and Universities}

As large organisations within which people learn, work, interact and live, universities inevitably impact on the health of their communities with institutional policy and practice, management styles, communication systems, decisionmaking processes and service design and provision all influencing well-being and quality of life (Abercrombie et al., 1998). Taking a whole university approach to health and well-being in universities ensures that staff, as well as student health and well-being, is an important consideration.

A focus on employee health has been strongly linked to performance and productivity, with the suggestion that universities need healthy and well-motivated workers if they are to deliver high-quality services (Health and Safety Executive, 2006, p. 1). Within a university workplace context, there are relatively few research papers that touch on salutogenic theory, exploring individual-level sense of coherence, and its relationship to stress and mental well-being in university staff (Bezuidenhout \& Cilliers, 2011; Kinman, 2008). There are many different groupings of staff within universities, but it is academics who feature most prominently in the literature in terms of stress and burnout. Kinchin (2019) focuses on the health of the system rather than the physical or mental health of individuals working there and introduces the concept of pedagogic health. Having identified the deficit model of pedagogic frailty, which stems from the idea that the professional environment can create tensions that impede the development of teaching practice, he suggests that salutogenesis, in contrast, pays more attention to the management of tension and utilising assets that contribute to wellness. This can thus be seen to offer links with the ideas of pedagogic health as a continuum between the extremes of pedagogic frailty and pedagogic resilience. In conclusion, Kinchin (2019) argues that before waiting for academics to experience difficulties through frailty within their teaching, moving to the proactive promotion of greater pedagogic health literacy across the campus is likely to have a more positive outcome for the institutional community.

In considering universities as a setting for health, it is relevant to revisit Antonovsky's (1987) assertion that sense of coherence as a health-promoting resource is developed and strengthened mainly in the years before a person is 30 . Although Eriksson and Mittelmark (2017) reflect that this assumption is not supported by more recent empirical 
research, which suggests that sense of coherence develops over the full life course, it remains that higher education is an important setting for researching and building an understanding of sense of coherence and for implementing interventions and programmes able to support its development. This is particularly pertinent in view of the fact that many university students belong to this age group and face a range of challenges in adapting to an unfamiliar environment and managing new academic and social demands (Chu et al., 2016). More widely, Hochwalder and Saied (Hockwälder \& Saied, 2018) reflect that university students are at a significant stage during their study and how well they manage this time can also link to their future professional and personal life. They argue that the SOC scale could be used to identify students' levels of SOC and then for universities to make efforts to support students in increasing it over their time with them. It is, therefore, not surprising that a larger number of studies have been undertaken exploring students' sense of coherence and its relationship to health behaviours, physical and/or mental health and quality of life.

Kuuppelomäki and Utriainen (2003) examined sense of coherence and its associations with smoking, drinking and physical exercise among students at a Finnish polytechnic, finding a positive correlation with physical activity but no association with smoking and drinking. Von Bothmer and Fridlund (2004) investigated students' self-rated health in relation to sense of coherence in a small Swedish university. They concluded that mean score for sense of coherence was similar for female and male students, but that a positive association between self-rated health and sense of coherence only existed for women. Research conducted in two universities in Poland explored the relationship between students' sense of coherence and health-related behaviour in 521 students, concluding that sense of coherence had a significant positive correlation with the intensity of pro-health behaviours (Binkowska-Bury \& Januszewicz, 2010). Reporting on a study conducted in four Indian colleges, Suraj and Singh (2011) reported a positive correlation between healthpromoting lifestyle profile scores and sense of coherence, whilst Rakizadeh and Hafezi (2015) conducted a study of 459 students at one university in Iran and found significant strong positive relationships between the three sense of coherence components and all domains in WHO's 26 item Quality of Life questionnaire. In a study undertaken among Chinese international undergraduate nursing students at an Australian university, He et al. (2011) found a significant negative correlation between acculturative stress and sense of coherence, concluding that there is a need for universities to offer appropriate support to overseas students.

Whilst these research papers provide insights into the experiences of staff and students at universities, most are not conceptualised or framed in relation to 'Health Promoting Universities' and neither engage with nor reflect an under- standing of ecological whole system thinking. There are, however, a few exceptions:

- Peker et al. (2011) reported on a study that examined the relationship between generalised resistance resources and sense of coherence among 566 dental students at Istanbul University. Informed by a commitment to Health Promoting Universities, empowerment and salutogenic theory, they found that a strong sense of coherence was significantly positively correlated with lower stress levels, higher social support levels, better self-rated health and a range of pro-health behaviours.

- Heiman (2004) reported on a study conducted in Israel, exploring the concept of the sense of coherence in relation to social support, coping styles and the stress experiences of university students. Whilst not contextualising the research within a healthy settings framework, she concludes that it would be valuable to focus on students and their interaction with the environment, using the concepts of stress, coping and social support as inseparable characteristics of a systems model.

- Graeser (2011), explicitly locating her research to settings-related theory, developed a University Sense of Coherence scale (combining the subcomponents of comprehensibility, manageability and meaningfulness) and conducted two studies with employees at a German university. The findings showed clear correlations between the organisational-level setting-based Sense of Coherence and health. Reflecting on these findings, she argued that cultural dimensions are the basis for an organisationbased Sense of Coherence, which plays a valuable role in shifting the focus from the individual to the organisation. She concluded that an organisation-based sense of coherence works in a dynamic way with individuals in that community. This research links well with the whole system perspective of Health Promoting Universities, acknowledging the importance of a university's ethos and culture and discussing how individuals interact with and feel part of it. This leads to learning in conditions conducive to mental health across an organisation.

\section{Promoting Health and Well-Being in the University Setting: Emerging Challenges and Responses}

The Health Promoting Universities movement, informed as it is by the settings perspective and salutogenic orientation (Kickbusch, 1996), faces a number of emerging challenges. Two of these are outlined below, which, though illustrated with reference to the UK experience, have global resonance.

First, the UK higher education sector's commitment to widening participation and the resulting diversification of the 
student profile (House of Commons, 2018) have, not surprisingly, coincided with (Thorley, 2017):

- Increasing levels of mental illness, mental distress and low well-being among students in higher education, as the student population comes to resemble more closely the country's demographic and socioeconomic profile

- Growing demand for student counselling, disability and well-being services

This has contributed to a high-profile media narrative of a 'student mental health crisis', fuelled in particular by an increase in student suicides (Dandridge, 2018); this trend has served as a catalyst for expansion and strengthening of university provision of advisory and therapeutic services that can respond to the full range of health, social and welfare needs presented by this broadened student population. Such responses are important to ensure that universities fulfil their duty of care and avoid negative impacts on student experience, retention and achievement. At the same time, there has been a growing appreciation that the student population comprises a range of 'communities' within which people are creating their own social networks as well as being offered opportunities to engage, participate and access services.

This increase in reported mental health problems has, on the one hand, served to heighten awareness of health as a key strategic and operational priority for universities and rapidly shift it up the institutional agenda. However, it has, on the other hand, catalysed a narrowing of focus away from the salutogenic Health Promoting Universities approach. As Dooris et al. (2019, p10) observe: 'whilst this represents an important opportunity to secure health as a sectoral priority, it also threatens to divert attention and resources from holistic and joined-up approaches by focusing primarily on treatment and service provision rather than wider prevention and health promotion and viewing "mental" health as somehow separate from other dimensions of wellbeing'.

Within the UK, whilst many universities are currently focusing resources onto tackling mental health problems with prioritisation of service delivery and early intervention, there has at the same time been strong advocacy for a more strategic and comprehensive response. Encouragingly, informed by the Okanagan Charter (2015) and Healthy Universities framework (Dooris et al., 2010), high-profile organisations such as Universities UK and Student Minds have called for wholeorganisation and whole-system approaches (Universities UK, 2015). Key developments supporting this include the Stepchange: Mentally Healthy Universities Framework (Universities UK, 2020), which articulates a vision for UK universities to be "places that promote mental health and wellbeing, enabling all students and all staff to thrive and succeed to their best potential', and the University Mental Health Charter (Hughes \& Spanner, 2019).
Second, the growing commitment to embedding health and well-being within the mainstream business of higher education has developed in tandem with the expectation that higher education will act sustainably in all that it does (International Sustainable Campus Network, 2018). Conceptually, sustainable development and health promotion both look beyond lifestyle influences, highlighting the intersection of environmental, social and economic determinants. With the publication of the 2030 agenda for sustainable development (United Nations, 2015), there has been a convergence of agendas: Climate change is no longer only seen as a sustainability issue, but also acknowledged to be the greatest twenty-first-century global public health threat (Costello et al., 2009); nature and green space are understood to be fundamental resources for good health as well as for a balanced ecosystem (van den Bogerd et al., 2018)); and influential commentators are calling for a new 'ecological public health' which highlights the essential connections between health, sustainability, equity and justice and recognises that human health ultimately depends on the health of ecosystems (Lang \& Rayner, 2012).

This convergence of agendas and dual expectation within higher education provides the perfect springboard to encourage a process of coordinated action to develop healthy, sustainable, low-carbon campuses that protect and promote the well-being of people, places and the planet, through taking steps to integrate good practice in key areas such as active travel, sustainable food and curriculum design (Orme \& Barna, 2010; Orme \& Dooris, 2010). However, such coordination can itself be challenging, as individuals, organisations and networks hold onto siloed ways of working in terms of existing systems and capacity (Dooris, 2013; Poland \& Dooris, 2010). Furthermore, it can also mitigate against adopting an explicitly salutogenic focus. In the same way that those working in health promotion seeking to promote health within a context dominated by a medical model focused on disease and pathogenesis, so those working in sustainable development operate within a system that tends to focus on how best to limit or mitigate detrimental impacts. In bridging silos and connecting agendas, it is helpful to appreciate the strong resonance between the salutogenic perspective and the emerging focus on 'regenerative' and 'restorative' sustainability (Brown, 2016; Robinson \& Cole, 2015). In both, a recurring challenge is to acknowledge and address the very real problems facing us - whether obesity, mental health, climate change or resource depletion - whilst asserting the potential not only to limit negative influence but also achieve net positive impacts and enhance human and planetary well-being. 


\section{Discussion}

When considering the implications for salutogenesis policy, practice and research relating to the university setting, it is valuable to explore developments and opportunities at three levels.

First, at international and national levels, the interest in the whole system Health Promoting Universities approach reflects the success of other programmes using a settings approach, such as Health Promoting Schools and Health Promoting Further Education. School-focused evidence reviews support a whole school approach, suggesting that effective programmes are likely to be complex, multifactorial and involve activity in more than one domain (StewartBrown, 2006; St Leger et al., 2010) whilst a review focused on further education concluded that "while it is not possible to state with certainty that multi-component, whole-settings approaches are more successful in college and university settings than one-off activities, the evidence points in this direction' (Warwick et al., 2008: 27). Echoing these findings, a study focused on higher education concluded that "embedding a "whole system" commitment to health into university structures/processes results in positive outcomes for students, staff and the organisation as a whole' (Newton, 2014).

Reflecting this growing interest, national networks have articulated ambitions and frameworks that are clearly salutogenic in focus. For example, the 'Quality Criteria for Health Promoting Universities' issued by the German Network of Health Promoting Universities (2010) state that 'A Health Promoting University is based on the concept of salutogenesis and focuses on the conditions and resources necessary for health'. Internationally, the Okanagan Charter (2015) - whilst not using salutogenic terminology - is explicit in its focus on enabling university communities to thrive and encouraging them to generate thriving, empowered, connected and resilient campus communities supported by a culture of wellbeing and contributing to community and planetary health.

Second, at the university level, there is evidence of a growing interest in implementing such a whole university approach, encompassing a concern to ensure promotive and protective factors for health, well-being and human flourishing. The availability of generalised and specific resistance resources (Mittelmark et al., 2017) is particularly important in enabling a strengthening sense of coherence for students, staff and other stakeholders in a university setting. Although these resources are discussed in relation to schools, we feel the concept can also be applied to Health Promoting Universities. Generalised resistance resources - evident through a university prioritising environments that are supportive for effective and productive learning, working and living - contribute in a general way to the development of a sense of coherence of many students and staff. Specific resis- tance resources - for example, counselling provision and advisory services targeted at specific groups of students or staff - would be present in a university but, unless particularly salient to individual students or staff, are unlikely to be widely used. However, a strong sense of coherence is understood to facilitate the uptake and use of particular specific resistance resources when they are needed.

It is clear, then, that there is scope for exploring further the concept of resistance resources in relation to universities and that developing a more nuanced understanding could be highly beneficial for all who live, learn, work, play and love on our campuses. Although generally not engaging directly with the language of salutogenesis, it is possible to discern examples that resonate. In the UK, for example, universities and their students' unions have responded to the student engagement, experience and mental health agendas by putting in place what can be understood as a combination of generalised and specific resistance resources. Student charters have been used to articulate intentions to create an appropriate learning culture and support students to reach their full potential (Department for Business, Innovation and Skills, 2011); student-led clubs and societies have been established spanning a range of interests and activities; and targeted services for students and staff have been set up in response to identified and perceived needs.

In guiding practice and research within an often large and complex setting such as a university, it is important to consider a number of connected questions: What are the likely mediators of these community effects? How can staff and students be supported to develop their sense of belonging? How can the institution as a whole provide a supportive context that can strengthen sense of place and sense of self? (Kickbusch, 1996).

Third, it is important to consider the interface between people within the university and the university as a context. In this respect, universities are complex, in that they involve students, staff and external stakeholders, and are located within wider communities. The Health Promoting Universities approach includes opportunities for individuals to be given a voice and shape policy, services, information and projects and can usefully explore how people interact and find meaning within the setting, appreciating that these interactions have the capacity to either support or impact negatively on well-being. Whilst it is important to acknowledge the reality of continuing health 'problems', illnesses and needs, the Health Promoting University approach must continue to assert its salutogenic focus, creating supportive environments and enabling its community to thrive and flourish.

It is fundamental that this multilevel approach to salutogenic policy and practice in universities is supported by a focus on salutogenic research. There is currently a lack of salutogenic research that focuses on health creation and 
maintenance and looks at the underpinning processes in higher education settings that are health-enhancing and strengthen 'sense of coherence' (i.e. comprehensibility, manageability and meaningfulness). This requires researchers to consider felt and expressed improvements in health and well-being within the context of a whole system orientation and to explore what a salutogenic orientation can do for the core business of universities. This would also contribute to the development of evaluative research and the strengthening of the evidence base for Health Promoting Universities.

\section{Conclusion and Challenges for the Future}

Looking to the future, the Health Promoting Universities approach offers enormous potential to support the creation and maintenance of health and flourishing of students, staff and the wider community. There are, though, challenges to face.

First, higher education as a sector does not exist primarily to promote health. In seeking to embed a commitment to health, it is therefore imperative that we are able to demonstrate and illustrate how investment in well-being can contribute to the delivery of core business goals.

Second, the language of 'health' still tends to be closely aligned with negative concepts of illness and disease. It will therefore be necessary to engage with 'pathogenic' perspectives and the very real problems facing universities as they seek to address both human and planetary health but to shift the orientation towards salutogenic and regenerative perspectives. Through exploring how health can be a resource to support core university business, it is possible to make a case for harnessing and strengthening positive assets and potentials - even if not explicitly using salutogenic language.

Third, many determinants of both illness and health and human potential are located outside of universities. This highlights the importance of strengthening the advocacy role of universities to call for action and become a powerful force for positive change, helping to create conditions that support well-being within universities, their local communities and society as a whole. It is evident that universities play an important role in training staff and educating students in ways that increase understanding of the determinants of health and health equity and unleash multisectoral innovation, creativity and passion for well-being, sustainability and social justice.

Within these contextual constraints, a student's sense of coherence is shaped by many aspects of experience evolving from comprehensibility, manageability and meaningfulness. Supporting the development of a student's sense of coherence in a university setting is therefore particularly challeng- ing. Chu et al. (2016) highlight that a university is an environment with many new demands, including academic, social and career challenges. How these factors are experienced by students at an individual, group and community level will impact on the development of a sense of coherence. A number of studies have undertaken measurements of students' sense of coherence within university settings. These include those that indicate a strengthening of sense of coherence linked to the intensity of pro-health behaviours (Binkowska-Bury \& Januszewicz, 2010), positive correlations with lower stress levels, higher social support levels and better self-related health and pro-health behaviours (Peker et al., 2011) and a higher level of acculturative stress among international students (He et al., 2011).

Discussing sectoral developments within higher education in the UK, Steuer and Marcs (2008) critique a perceived overemphasis on economic development, which they see as fuelling individual competitiveness. In response, they advocate a transformative approach to quality in higher education that serves the dual purpose of enhancing both personal and collective well-being - prioritising features such as enjoyment and fulfilment, autonomy and reciprocity, connectedness and belonging, and empowerment and ability to effect change. Such an approach offers a potential way forward for strengthening comprehensibility, manageability and meaningfulness within the university setting.

\section{References}

Abercrombie, N., Gatrell, T., \& Thomas, C. (1998). Universities in the twenty-first century. In A. Tsouros, G. Dowding, J. Thomson, \& M. Dooris (Eds.), Health promoting universities: Concept, experience and framework for action. Copenhagen. Retrieved October 21, 2020, from www.euro.who.int/document/e60163.pdf.

Antonovsky, A. (1987). Unravelling the mystery of health. Jossey Bass. Antonovsky, A. (1996). The salutogenic model as a theory to guide health promotion? Health Promotion International, 11(1), 11-18.

Asean University Network-Health Promotion Network. (2017). AUN healthy university framework. Mahidol University, Thailand. Retrieved October 21, 2020, from http://www.aunsec.org/pdf/publication/Healthy\%20University\%20Framework\%20Final.pdf.

Beattie, A. (1995). Editorial: New agendas for student health. Health for All 2000 News, 31, 2-3.

Bezuidenhout, A., \& Cilliers, F. (2011). Age, burnout, work engagement and sense of coherence in female academics at two south African universities. South African Journal of Labour Relations, 35, 61-80.

Binkowska-Bury, M., \& Januszewicz, P. (2010). Sense of coherence and health-related behaviour among university students - A questionnaire survey. Central European Journal of Public Health, 18(3), $145-150$.

Brennan, J., King, R., \& Lebeau, Y. (2004). The role of universities in the transformation of societies. Synthesis report. Association of Commonwealth Universities/Open University.

Brown, M. (2016). Future REstorative. Working towards a new sustainability. RIBA Publishing. 
Centre for Urban and Regional Development Studies. (1994). Universities and communities. CVCP.

Chu, J., Khan, M., Jahn, H., \& Kraemer, A. (2016). Sense of coherence and associated factors among university students in China: Crosssectional evidence. BMC Public Health, 16, 336.

Coffey, M., \& Coufopoulos, A. (2010). Creating a 'health promoting curriculum' to inform the development of a health promoting university: A case study. International Journal of Health Promotion and Education, 48, 4-8.

Costello, A., Abbas, M., Allen, A., et al. (2009). Managing the health effects of climate change. The Lancet, 373, 1693-1733.

Crouch, R., Scarffe, P., \& Davies, S. (2006). Guidelines for mental health promotion in higher education. Retrieved October 21, 2020, from http://www.mentalhealthpromotion.net/ resources/final_guidelines_for_mental_health_promotion in_higher_education-07.doc\#: :text=Guidelines $\% 20$ for $\% 20$ Menta1\%20Health\%20Promotion $\% 20$ in $\% 20$ Higher $\% 20$ Education,developing $\% 20$ policies $\% 2 \mathrm{C} \% 20$ procedures $\% 20$ and $\% 20$ activities $\% 20$ promoting $\% 20$ mental $\% 20$ health.

Dandridge, N. (2018). Mental health and wellbeing: A priority. Office for Students. Retrieved October 21, 2020, from https://www. officeforstudents.org.uk/news-blog-and-events/our-news-and-blog/ mental-health-and-wellbeing-a-priority/.

Davies, J. K., \& Hall, C. (2011). Establishing the University of Brighton as a health promoting university: A pilot project final report. University of Brighton.

Department for Business, Innovation and Skills. (2011). Student charter group: Final report. Crown Copyright. Retrieved October 21, 2020, from http://www.bis.gov.uk/assets/biscore/higher-education/ docs/s/11-736-student-charter-group.pdf.

Doherty, S., Cawood, J., \& Dooris, M. (2011). Applying the whole system settings approach to food within universities. Perspectives in Public Health, 131, 217-224.

Dooris, M. (1998). Case study: The university as a setting for sustainable health-University of Central Lancashire. In A. Tsouros, G. Dowding, J. Thompson, \& M. Dooris (Eds.), Health promoting universities: Concept, experience \& framework for action (pp. 97-110). WHO Regional Office for Europe.

Dooris, M. (1999). The health promoting university as a framework for promoting positive mental wellbeing-A discourse on theory and practice. International Journal of Mental Health Promotion, 1, 34-44.

Dooris, M. (2001). The 'health promoting university': A critical exploration of theory and practice. Health Education, 101, 51-60.

Dooris, M. (2004). Joining up settings for health: A valuable investment for strategic partnerships? Critical Public Health, 14, 49-61.

Dooris, M. (2006). Healthy settings: Challenges to generating evidence of effectiveness. Health Promotion International, 21, 55-65.

Dooris, M. (2009). Holistic \& sustainable health improvement: The contribution of the settings-based approach to health promotion. Perspectives in Public Health, 129, 29-36.

Dooris, M. (2013). Bridging the silos: Towards healthy and sustainable settings for the $21^{\text {st }}$ century. Health \& Place, 20, 39-50.

Dooris, M., \& Doherty, S. (2009). National Research and development project on healthy universities: Final report. Higher Education Academy Health Sciences and Practice Subject Centre. Retrieved October 21, 2020, from https://core.ac.uk/display/6113091

Dooris, M., Cawood, J., Doherty, S., \& Powell, S. (2010). Healthy universities: Concept, model and framework for applying the healthy settings approach within higher education in England. Final project report-March 2010. UCLan. Retrieved October 21, 2020, from https://healthyuniversities.ac.uk/wp-content/uploads/2016/10/HUFinal_Report-FINAL_v21.pdf.
Dooris, M., Doherty, S., Cawood, J., \& Powell, S. (2012). The healthy universities approach: Adding value to the higher education sector. In A. Scriven \& M. Hodgins (Eds.), Health promotion settings: Principles and practice. Sage.

Dooris, M., Farrier, A., Doherty, S., Holt, M., Monk, R., \& Powell, S. (2018). The U.K. healthy universities self-review tool: Whole system impact. Health Promotion International, 32(3), 448-457.

Dooris, M., Powell, S., \& Farrier, A. (2018). Healthy universities: Whole university leadership for health, Wellbeing \& Sustainability. Leadership Foundation for Higher Education/Advance HE. ISBN: 978-1-912137-92-3.

Dooris, M., Powell, S., \& Farrier, A. (2019). Conceptualising the 'whole university' approach: An international qualitative study. Health Promotion International, 35(4), 730-740.

Epigeum Ltd. (2012). The university context: An introduction. The role of universities. Retrieved October 21, 2020, from https://www. epigeum.com/downloads/ulm_accessible/uk/01_intro/html/course_ files/in_2_10.html .

Eriksson, M., \& Mittelmark, M. (2017). The sense of coherence and its measurement. In M. Mittelmark et al. (Eds.), The handbook of Salutogenesis (pp. 97-106). Springer.

Faculty of Public Health Medicine. (1995). Health for All 2000 News, $31,1-20$

German Network of Health Promoting Universities. (2010). Quality criteria of Health Promoting Universities. Retrieved October 21, 2020, from www.gesundheitsfoerdernde-hochschulen.de/Inhalte/E_ Gefoe_HS_internat/AGH_INFO_QUALITY_CRITERIA_HPU_ LOGO_ENG.pdf

Graeser, S. (2011). Salutogenic factors for mental health promotion in work settings and organisations. International Review of Psychiatry, $23,508-515$.

Grant, A., Kester, G., Donnelly, N., \& Hale, B. (2002). Reducing the risk of student suicide: Issues and responses for higher education institutions (UUK management guidance series). UUK/SCOP.

He, F., Lopez, V., \& Leigh, M. (2011). Perceived acculturative stress and sense of coherence in Chinese nursing students in Australia. Nurse Education Today, 32(4), 345-350.

Heiman, T. (2004). Examination of the salutogenic model, support resources, coping style, and stressors among Israeli university students. Journal of Psychology, 138, 505-520.

Health and Safety Executive (HSE). (2006). Healthy workplace, healthy workforce, better business delivery: Improving service delivery in universities and colleges through better occupational health. HSE.

Higher Education Statistics Agency (HESA). (2020a). Higher Education Student Statistics: UK, 2018/19 - Student numbers and characteristics. Retrieved October 21, 2020, from https://www. hesa.ac.uk/news/16-01-2020/sb255-higher-education-studentstatistics/numbers .

Higher Education Statistics Agency (HESA). (2020b). Higher Education Staff Statistics: UK, 2018/19. Retrieved October 21, 2020, from https://www.hesa.ac.uk/news/23-01-2020/ sb256-higher-education-staff-statistics

Hockwälder, J., \& Saied, V. (2018). The relation between sense of coherence and daily hassles among university students. Health Psychology and Behavioral Medicine, 6(1), 329-339.

House of Commons. (2018). Widening participation strategy in higher education in England. In Briefing paper 8204. House of Commons.

Hughes, G., \& Spanner, L. (2019). The university mental health charter. Student Minds. Retrieved October 21, 2020, from https://www. studentminds.org.uk/charter.html

ICEF Monitor. (2018). Study projects dramatic growth for global higher education through 2040. Retrieved 
21 Oct 2020, from http://monitor.icef.com/2018/10/ study-projects-dramatic-growth-global-higher-education-2040

Innstrand, S. T., \& Christensen, M. (2018). Healthy universities. The development and implementation of a holistic health promotion intervention programme especially adapted for staff working in the higher educational sector: The ARK study. Global Health Promotion, 27(1), 68-76.

International Sustainable Campus Network. (2018). Sustainable Campus Charter. Retrieved October 21, 2020, from https:// international-sustainable-campus-network.org/download/250/

Kickbusch, I. (1996). Tribute to Aaron Antonovsky-'what creates health'? Health Promotion International, 11, 5-6.

Kinchin, I. (2019). The salutogenic management of pedagogic frailty: A case of educational theory development using concept mapping. Education Sciences, 9(2), 157.

Kinman, G. (2008). Work stressors, health and sense of coherence in U.K. academic employees. Educational Psychology, 28, 823-835.

Knight, A., \& La Placa, V. (2013). Healthy universities: Taking the University of Greenwich healthy universities initiative forward. International Journal of Health Promotion and Education, 51, $41-49$.

Kuuppelomäki \& Utriainen. (2003). A 3 year follow-up study of health care students' sense of coherence and related smoking, drinking and physical exercise factor. International Journal of Nursing Studies, 40(4), 383-388.

Lang, T., \& Rayner, G. (2012). Ecological public health: The 21st century's big idea? BMJ, 345, e5466-e5420.

McGowan, T. (2015). Should universities promote employability? Theory and Research in Education, 13(3), 267-285.

Marshall, L., \& Morris, M. (Eds.). (2011). Taking forward wellbeing in higher education: Reflections in theory and practice. University of Brighton Press.

Meier, S., Stock, C., \& Krämer, A. (2006). The contribution of health discussion groups with students to campus health promotion. Health Promotion International, 22, 28-36.

Mittelmark, M. B., Sagy, S., Eriksson, M., Bauer, G., Pelikan, J. M., Lindström, B., \& Espnes, G. A. (2017). The handbook of Salutogenesis. Springer Nature.

Newton, J. (2014). Can a university be a 'healthy university'? An analysis of the concept and an exploration of its operationalisation through two case studies. PhD thesis. London South Bank University.

Newton, J., Dooris, M., \& Wills, J. (2016). Healthy universities: An example of a whole-system health-promoting setting. Global Health Promotion, 23(Suppl. 1), 57-65.

Okanagan Charter for Health Promoting Universities and Colleges. (2015). International conference health promoting universities and colleges. Kelowna. Retrieved October 21, 2020, from https:// internationalhealthycampuses2015.sites.olt.ubc.ca/files/2016/01/ Okanagan-Charter-January13v2.pdf.

Orme, J., \& Barna, S. (2010, December). Education for sustainable development: The role of Healthy Universities. Healthy Universities. Issue 3. Retrieved October 21, 2020, from https:// healthyuniversities.ac.uk/wp-content/uploads/2010/12/HUNewsletter-Issue-3.pdf.

Orme, J., \& Dooris, M. (2010). Integrating health and sustainability: The higher education sector as a timely catalyst. Health Education Research, 25, 425-437.

Peker, K., Bermek, G., \& Uysal, O. (2011). Factors related to sense of coherence among dental students at Istanbul University. Journal of Dental Education, 76(6), 774-782.
Poland, B., \& Dooris, M. (2010). A green and healthy future: A settings approach to building health, equity and sustainability. Critical Public Health, 20(3), 281-298.

Polymerou, A. (2007). Alcohol and drug prevention in colleges and universities: A review of the literature. Mentor UK.

Rakizadeh, E., \& Hafezi, F. (2015). Sense of coherence as a predictor of quality of life among Iranian students living in Ahvaz. Oman Medical Journal, 30(6), 447-454.

Robinson, J., \& Cole, R. (2015). Theoretical underpinnings of regenerative sustainability. Building Research \& Information, 43(2), 133-143.

Rootman, I., Goodstadt, M., Hyndman, B., McQueen, D., Potvin, L., Springett, J., et al. (Eds.). (2001). Evaluation in health promotion: Principles and perspectives. WHO Regional Office for Europe.

Royal College of Psychiatrists. (2011). Mental health of students in higher education. Council report CR166. RCP.

Schwartz, S. (2003, May 16). The higher purpose. Times Higher Education. Retrieved October 21, 2020, from http://www.timeshighereducation.co.uk/176727.article.

Shutler-Jones, K. (2011). Improving performance through wellbeing \& engagement - essential tools for a changing HE landscape. Retrieved October 21, 2020, from https://usha.org.uk/images/stories/files/wellbeing-final-report-2011-web.pdf.

St Leger, L., Young, I., Blanchard, C., \& Perry, M. (2010). Promoting health in schools: From evidence to action. International Union for Health Promotion and Education. Retrieved October 21, 2020, from https://www.iuhpe.org/images/PUBLICATIONS/THEMATIC/ HPS/Evidence-Action_ENG.pdf.

Steuer, N., \& Marcs, N. (2008). University challenge: Towards a wellbeing approach to quality in higher education. New Economics Foundation.

Stewart-Brown, S. (2006). What is the evidence on school health promotion in improving health or preventing disease and, specifically, what is the effectiveness of the health promoting schools approach? Health evidence network report. WHO Regional Office for Europe. Retrieved October 21, 2020, from www.euro.who.int/document/ e88185.pdf.

Stock, C., Milz, S., \& Meier, S. (2010). Network evaluation: Principles, structures and outcomes of the German working group of health promoting universities. Global Health Promotion, 17, 25-32.

Stock, C., Wille, L., \& Krämer, A. (2001). Gender-specific health behaviors of German university students predict the interest in campus health promotion. Health Promotion International, 16, 145-154.

Suraj, S., \& Singh, A. (2011). Study of sense of coherence health promoting behaviour in north Indian students. Indian Journal of Medical Research, 134, 645-652.

Thorley, C. (2017). Not by degrees. Improving student mental health in the U.K.'s universities. Institute for Public Policy Research.

Tsouros, A., Dowding, G., Thomson, J., \& Dooris, M. (Eds.). (1998). Health promoting universities: Concept, experience and framework for action. WHO Regional Office for Europe. Retrieved October 21, 2020, from www.euro.who.int/document/e60163.pdf.

UK Healthy Universities Network. (undated). Healthy Universities SelfReview Tool. Retrieved 20 October, 2020, from https://healthyuniversities.ac.uk/toolkit-and-resources/self-review-tool/

United Nations. (2015). Transforming our world. The 2030 agenda for sustainable development. United Nations.

Universities, UK. (2000). Guidelines on student mental health policies and procedures for higher education. Universities UK.

Universities UK. (2015). Student mental wellbeing in higher education. Good practice guide. Universities UK. Retrieved 20 October, 2020 
from https://www.universitiesuk.ac.uk/policy-and-analysis/reports/ Documents/2015/student-mental-wellbeing-in-he.pdf.

Universities UK. (2020). Stepchange: Mentally healthy universities. Universities UK. Retrieved 20 October, 2020 from https://www. universitiesuk.ac.uk/policy-and-analysis/reports/Pages/stepchangemhu.aspx.

UPP Foundation Civic University Commission. (2019). Truly civic. Strengthening the connection between universities and their places. London.

Usher, W. (2019). Living in quiet desperation: The mental health epidemic in Australia's higher education. Health Education Journal, 79(2), 138-151.

van den Bogerd, N., Dijkstra, S. C., Seidell, J. C., \& Maas, J. (2018). Greenery in the university environment: Students' preferences and perceived restoration likelihood. PLoS One, 13(2), e0192429. Retrieved October 21, 2020, from https://journals.plos.org/plosone/ article id=10.1371/journal.pone .0192429
Von Bothmer \& Fridlund. (2004). Self-rated health among university students in relation to sense of coherence and other personality traits. Scandinavian Journal of Caring Sciences, 17(4), 347-357.

Warwick, I., Statham, J., \& Aggleton, P. (2008). Healthy and health promoting colleges-Identifying an evidence base. Thomas Corum Research Unit, University of London.

Waterworth, C., \& Thorpe, A. (2017). Applying the Okanagan charter in Aotearoa New Zealand. Journal of the Australian and New Zealand Student Services Association, 25(1), 49-61. https://janzssa. scholasticahq.com/article/1338-applying-the-okanagan-charter-inaotearoa-new-zealand

World Health Organization (WHO). (1986). Ottawa charter for health promotion. WHO.

Xiangyang, T., Lan, Z., Xueping, M., Tao, Z., Yuzhen, S., \& Jagusztyn, M. (2003). Beijing health promoting universities: Practice and evaluation. Health Promotion International, 18, 107-113.

Open Access This chapter is licensed under the terms of the Creative Commons Attribution 4.0 International License (http://creativecommons. $\mathrm{org} /$ licenses/by/4.0/), which permits use, sharing, adaptation, distribution and reproduction in any medium or format, as long as you give appropriate credit to the original author(s) and the source, provide a link to the Creative Commons license and indicate if changes were made.

The images or other third party material in this chapter are included in the chapter's Creative Commons license, unless indicated otherwise in a credit line to the material. If material is not included in the chapter's Creative Commons license and your intended use is not permitted by statutory regulation or exceeds the permitted use, you will need to obtain permission directly from the copyright holder. 